\title{
A Constraint-based Analysis of Velar Affrication in Najdi vs. Hijazi Arabic
}

\author{
Mahmoud S. Al Mahmoud \\ Dept. of English, Imam University, Riyadh, Saudi Arabia \\ E-mail:msmahmoud@imamu.edu.sa
}

Received: August 23, 2020 Accepted: September 20, 2020 Published: September 22, 2020

doi:10.5296/elr.v6i2.17551 URL: https://doi.org/10.5296/elr.v6i2.17551

\begin{abstract}
This paper attempts to account for the velar affrication in Najdi Arabic (NA) and its absence in Hijazi Arabic (HA). While NA consistently alters /k/ into [ts], and /g/ into [dz], HA retains the velars and as such is more faithful to standard Arabic. The analysis follows from an Optimality-Theoretic (OT) framework (Prince and Smolensky, 1993) explicating different constraint interactions and introducing new markedness constraints. It is argued that the realizations of the velars as $[\mathrm{k}]$ and $[\mathrm{g}]$ are in free variation distribution with their allophonic affricate counterparts [ts] and [dz], respectively, although the two variants of the same phoneme alternate under phonologically conditioned contexts.
\end{abstract}

Keywords: Velar affrication, Najdi Arabic, Fronting, Optimality Theory

\section{Introduction}

The analysis of many Arabic dialects remain largely descriptive, with few in-depth comparisons between Modern Standard Arabic and its divergent variants. Arabic as a language ranks sixth among the widely spoken languages of the world, and is the native language for over 186 million speakers and the liturgical language for a far greater number. It belongs to the Semitic group of languages; one that descends from an even larger family called Afro-Asiatic (Al-Sharkawi, 2016). Three varieties of Arabic are still in use today:

Classical Arabic (CA): the language of the Holy Qu'ran and classical poetry, dating back more than 1600 years.

Modern Standard Arabic (MSA): the language of today's media and the one officially taught in schools and spoken in formal settings.

Dialectical Arabic (DA): the most varying type of spoken Arabic (Watson, 2007). It is everyday language spoken by Arabs in many countries such as: Yemen, Iraq, Kuwait, Jordan, Saudi Arabia, Oman, Syria, Egypt, Morocco, Tunisia, Algeria, United Arab Emirates, Lebanon, 


\section{Macrothink}

Qatar, Sudan, Libya, Bahrain and Mauritania. Nonetheless, each country has its own version of dialectal Arabic.

One of the well-known dialects spoken in the Najd region in the central part of Saudi Arabia mostly by a sedentary population is Najdi Arabic (Ingham, 1994); Hijazi Arabic is commonly found in the northwestern part of the Arabian Peninsula. Both dialects are widely known and spoken nowadays in Saudi Arabia. Though affrication of the velars $/ \mathrm{k} /$ and $/ \mathrm{g} /$ occurs in a number of other Arabic dialects such as Janbui in Saudi Arabia, or Gulf Arabic, spoken in the GCC countries, the focus of this paper will be on the behavior of velars in Najdi and Hijazi Arabic.

The fronting of the velars $/ \mathrm{k} /$ and $/ \mathrm{g} /$ into [ts] and [dz], respectively, is widely attested in Najdi, but non-existent in Hijazi, to my knowledge. Historically, the lack of velar affrication puts HA more on a par with standard Arabic, understandably so since old Hijazi was the language in which the Qu'ran was scribed.

\section{Velar Affrication in NA vs. HA}

Two native speakers of Arabic provided the data for this study; a 26-year-old male college graduate with a major in Arabic language served as the informant for the Najdi dialect. He has lived all his life in the central region of Saudi Arabia, Riyadh, and is born into a Najdi family. The Hijazi informant is a 29-year-old college graduate with a major in Islamic Studies who has lived all his life in the Hijaz region, Jeddah, and was raised in a Hijazi family. Both subjects were aware of the purpose of the study and they were queried for data on velar affrication by the author. For the purpose of this study, the following descriptive matrix of featural values is assumed for the Arabic vowels (adapted from Spencer, 1995):

Table 1. Arabic vowel matrix of feature values

\begin{tabular}{lccccccccccc}
\hline & $\mathrm{i}$ & $\mathrm{I}$ & $\mathrm{e}$ & $\varepsilon$ & $\mathrm{a}$ & $\mathrm{u}$ & $\mathrm{u}$ & $\mathrm{o}$ & $\mathrm{a}$ & $\Lambda$ & - \\
\hline High & + & + & - & - & - & + & + & - & - & - & + \\
Low & - & - & - & - & + & - & - & - & + & - & - \\
Back & - & - & - & - & - & + & + & + & + & + & + \\
Round & - & - & - & - & - & + & + & + & - & - & - \\
ATR & + & - & + & - & - & + & - & + & - & - & - \\
\hline
\end{tabular}

\subsection{Affrication of the Velar $/ \mathrm{k} /$}

A qualitative analysis of the data elicited from the NA and HA informants shows clear cases of velar affrication only in Najdi Arabic, however. Consider the following examples (Note 1):
(1) $/$ kis/ $\rightarrow$
NA. [tsis] [kis]
HA. [kis] 'bag' (mas.)
(2) $/$ dik $/$ i
NA. [dits] [dik]
HA. [dik] 'rooster' (mas.)
(3) $/$ S Ilk/ $\rightarrow$

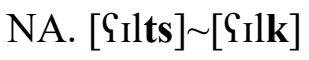
HA. [Gılk] 'chewing gum'
(4) $/$ keIf/ $\rightarrow$
NA. [tsef] [kef]
HA. [kef] 'how'
(5) $/ \mathrm{k} \varepsilon \mathrm{lb} / \quad \rightarrow$
NA. [ts $\varepsilon \mathbf{l b}] \sim[\mathbf{k} \varepsilon l b]$
HA. [kelb] 'dog' (mas.) 


\section{Macrothink}

The forms on the far left are standard Arabic and are often argued by phonologists to be the input to many Arabic dialects. Note how Najdi Arabic systematically alternates between the affricated and non-affricated forms; NA affricates the velar voiceless stop $/ \mathrm{k} /$ into [ts], although the velar status can still be maintained for some speakers. This phonological change takes place whether the velar is syllable-initial as in (1), (4) and (5), or syllable final as in (2) and (3); prevocalic as in (1), (4) and (5) or postvocalic as in (2) and (3). By contrast, Hijazi Arabic preserves the velar plosive in all examples. Typically, all affricates have to be homorganic (Roach, 2000); that is, the consonants in the affricate have to share the same (or similar) place of articulation with each other. The [ts] substitute for $/ \mathrm{k} /$ is an affricate that is made up of an alveolar plosive /t/ followed by an alveolar fricative $/ \mathrm{s} /$. Both elements of the affricate share the voiclessness status of the velar $/ \mathrm{k} /$ as well as the same place of articulation, both are alveolar.

Further examination of the data indicates that velar affrication is not limited to monosyllabic words (Note 2):

(6) $/ \mathbf{k} \varepsilon$.'rim/ $\rightarrow$ NA. [tsə.'rim] [kə.'rim]

HA. [ke.'rim] 'generous'

(7) /'ka.mil/ $\rightarrow$ NA. ['tsa.mil] ['ka.mil]

HA. ['ka.mil] 'perfect/full'

(8) $/$ 'ka.trb/ $\rightarrow$ NA. ['tsa.trb] ['ka.tib]

HA. ['ka.tib] 'writer' (mas.)

(9) /'sa.lik/ $\rightarrow$ NA. ['sa.lits] ['sa.lık]

HA. ['sa.lik] 'passable (road)'

The words in (6-9) are all disyllabic and the velar undergoes (optional) affrication in Najdi. It is important to note that stress placement has no obvious effect on the application of affrication; in (6) and (9) the velar occurs in an unstressed syllable, while in (7) and (8) it occurs in a stressed syllable. HA as stated before retains the velar and appears to be more faithful in resisting affrication to standard Arabic than Najdi.

\subsection{Affrication of the Velar /g/}

The discrepancy between NA and HA in the nonobligatory affrication of the voiceless velar $/ \mathrm{k} /$ is also maintained in its voiced counterpart, $/ \mathrm{g} /$. Again, the pattern of affrication in NA and lack of it in HA is observed in monosyllabic and disyllabic words:
(10) $/ \mathbf{q} \varepsilon \mathrm{lb} /$
$\rightarrow$
NA. $[\mathbf{d z} \varepsilon l b] \sim[\mathrm{g} \varepsilon \mathrm{lb}]$
HA. [gelb]
'opposite'
(11) /rizq/
NA. [rIzdz] $[$ rIzg]
HA. [rIzg]
'provision'
(12) /'PIq.lib/ $\rightarrow$
NA. ['?Idz.lib] ['?ıg.lib]
HA. ['PIg.lıb]
'flip' (imp.)
(13) /'la.siqq/ $\rightarrow$
NA. ['la.sistz] ['la.sisig]
HA. ['la.sig]
'sticky'

Considering the standard Arabic forms as the input for the dialectal forms, the uvular $/ \mathrm{q} /$ in standard Arabic is regularly realized as [g] in dialectal Arabic, although other realizations of the uvular exist such as [?] in Egyptian and Syrian Arabic, or [в] in some Kuwaiti dialects. The uvular /q/ occurs syllable initially in (10) and syllable finally in (11) and is realized in these monosyllabic words as either the velar [g] or its affricate allophone [dz]. The same is also true for polysyllabic words whether the uvular appears in stressed syllables as in (12) or unstressed syllables as in (13). HA, on the other hand, realizes the uvular /q/ as the voiced velar [g], with no affrication possible. Interestingly, the affricate [dz] is homorganically composed of a voiced alveolar stop /d/ followed by a voiced alveolar fricative /z/; both share the same place of articulation and both are voiced as the velar [g] is. 


\subsection{Lack of Velar Affrication in NA}

Further data elicited from the NA informant in this study reveal some intriguing cases where velar affrication fails to apply. Consider the following examples:
(14) $/ \mathbf{k o m} /$
$\rightarrow$ NA. $[\mathrm{k} v \mathrm{~m}] \sim *[\mathbf{t s} \mho \mathrm{m}]$
'cuff'
(15) $/ \mathrm{Jok} /$

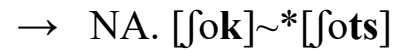
'thorn'
(16) $/ \mathrm{kvl} /$
$\rightarrow$ NA. [kol] * *[tsol]
'all of'
(17) /'rok.bəh/ $\rightarrow$ NA. ['rok.bəh] *['rots.bəh]
'knee' (fem.)
(18) /meb.'ruk
NA. [meb.'ruk] * [meb.'ruts]
'blessed'

The alternation between the affricated and non-affricated form of the velar plosive $/ \mathrm{k} /$ in the NA data above is unattainable. The affricate [ts] is judged to be unacceptable by the NA informant, who emphasized that the velar has to be preserved as [k] and cannot be changed. This lack of affrication also applies to the voiced velar plosive $/ \mathrm{g} /$ :
(19) $/$ foq/
$\rightarrow$ NA. [fog] * [fodz $]$
'above'
(20) $/ \mathbf{q a m} /$
$\rightarrow$ NA. $[$ gam $] \sim^{*}[$ dzam $]$
'(he) stood up'
(21) $/ \mathbf{q} \Lambda \mathrm{lb} /$
$\rightarrow$ NA. $[\mathbf{g} \Lambda \mathrm{lb}] \sim *[\mathbf{d z} \Lambda \mathrm{lb}]$
'heart'
(22) /qu.'rud/
$\rightarrow$ NA. [grud] $*$ [dzrud]
'monkeys'
(23) /'q $\mathbf{\Lambda}$. bəl/
$\rightarrow$ NA. ['g $\Lambda$. bəl] $\sim *[' d z \Lambda . b ə l]$
'before'

Similar to the examples (14-18), the words in (19-23) contain the standard Arabic uvular/q/, which is fronted to the velar [g] in dialectal Arabic. Note how NA disallows affrication of the uvular in these words regardless whether they are monosyllabic or multisyllabic. The NA informant in the study confirms that none of these words can be spoken with $[\mathrm{dz}]$ for $/ \mathrm{g} /$.

\section{Discussion}

A cursory look at the data in Section 2 provided by the native informants of NA and HA suggests that while velar affrication is impossible in HA, its occurrence in NA is quite common. It appears that HA is more faithful to the standard form when it comes to the realization of the velar $/ \mathrm{k} /$ than NA is, which alternates between the velar $[\mathrm{k}]$ and its affricate counterpart [ts]. In realizing the uvular /q/, both dialects diverge from the standard form. While HA substitutes the allophone [g] for /q/, NA introduces further the allophone [dz], in addition to [g]. It is important to note that the alternation in NA velar affrication is noncompulsory and the allophones of each velar phoneme are said to be in free variation. In other words, NA has two realizations for each of the phonemes $/ \mathrm{k} /$ and $/ \mathrm{q} /$. The phoneme $/ \mathrm{k} /$ can either be realized as [k] (i.e. the faithful allophone), or as the affricate allophone [ts]. The phoneme /q/ can be realized either as the velar [g], or as the affricate allophone [dz]. The pattern in the 2.3 data, however, is problematic for this generalization since neither [ts] nor $[\mathrm{dz}]$ can surface as possible allophones for the phonemes $/ \mathrm{k} /$ and $/ \mathrm{q} /$, respectively. The question is why?

\subsection{Affrication and Vowel Quality}

The data in Section 2 show an ostensible pattern in NA of velar affrication (Sections 2.1 and 2.2) and absence of affrication (Section 2.3). HA, on other hand, is more uniform in its prohibition of velar affrication. Careful examination of the data does not permit for a stress-based or syllable count-based explanation; velar affrication takes place irrespective of 
stress placement or the position of the syllable in which the velar occurs (i.e. mono- or multi-syllabic words).

One explanation quite popular in the traditional Arabic grammar (Sibawayh, 2009, p. 200) has to do with gender (Note 3). It is assumed that if the gender of the word referent is masculine, then affrication is not possible. If, however, the gender is feminine, then the velar can be realized as an affricate:
(24) $/$ 'fi.ka/ $\rightarrow$ [fik]
'in you (mas.)'
(25) /'fi.ki/ $\rightarrow$ [fits]
'in you (fem.)'

In (24) the addressee is masculine and $/ \mathrm{k} /$ undergoes no change. In (25) the addressee is feminine and the velar is affricated to [ts]. Nonetheless, the examples outlined in Section 2 bear little support for such argument. The words in (1), (2), (5), (8) all have masculine reference, yet affrication applies whereas (17), for instance, is feminine with no affrication. In short, a gender-based explanation is inadequate and falls short of accounting for the pattern of velar affrication the data present.

Further scrutiny of the data in Section 2 leads to an argument of velar affrication pattern based on the quality of the vowel in the word. Note that in all of the words in Sections 2.1 and 2.2, the velar sound is positioned next to a front vowel; the words: /kis/ 'bag', /9ılk/ 'chewing gum', /kerf/ 'how', and /kelb/ 'dog', /qعlb/ 'opposite' and /rizq/ 'provision' all contain vowels that are articulated in the front of the mouth. On the other hand, words where affrication fails to apply in Section 2.3 are made up of central or back vowels (non-front vowels): /kum/ 'cuff', / /ok/ 'thorn', /meb.'ruk/ 'congratulations', /foq/ 'above', /qam/ '(he) stood up', /qslb/ 'heart'. None of the words provided by the informant that have back or central vowels within the same syllable exhibited velar affrication, and vice versa. Thus, it seems that a vowel-based account of affrication in Najdi captures the alternation between the non-affricated and affricated allophones of the velar plosive.

Such analysis is not new, and previous studies have indicated that vowels have a role in the behavior of velar sounds. Johnstone (1967), among others, points out that velar consonants tend to be fronted when being near front vowels. In describing the phonology of the Shahran tribe Arabic, Al-Shahrani (1988) expounds on the status of affricates in a number of related dialects in the Arabian Peninsula. He treats [ts] and [dz] as the affricate reflexes of Classical Arabic $/ \mathrm{k} /$ and $/ \mathrm{q} /$, but settles for a descriptive account and gives no rule or formal explanation for affrication.

\subsection{Formal Analysis}

\subsubsection{Optimality Theory}

A basic notion in the Optimality Theory (Prince and Smolensky, 1993) is that for each input language creates an infinite number of potential outputs; the (Gen)erator function draws on the Lexicon of a language to generate an infinite number of outputs for a specific input. Language then chooses the right phonological output via input-output correspondence relations. Output forms are subjected to the function of Eval(uator) and a competition-like assessment takes place; the optimal candidate, which gets to be the actual output in language, is usually determined by its least serious violation(s) of a set of violable constraints. The evaluation or assessment process follows linearly: output forms are first evaluated on the 


\section{Macrothink}

highest ranked constraint, and any violating candidate is excluded from the competition. The process of output exclusion continues by the rest of the hierarchally ranked constraints until one output remains either by virtue of violating no constraint at all, or violating the lowest ranked one. A schematic mapping of the assessment and elimination process in OT is provided in Figure 1:

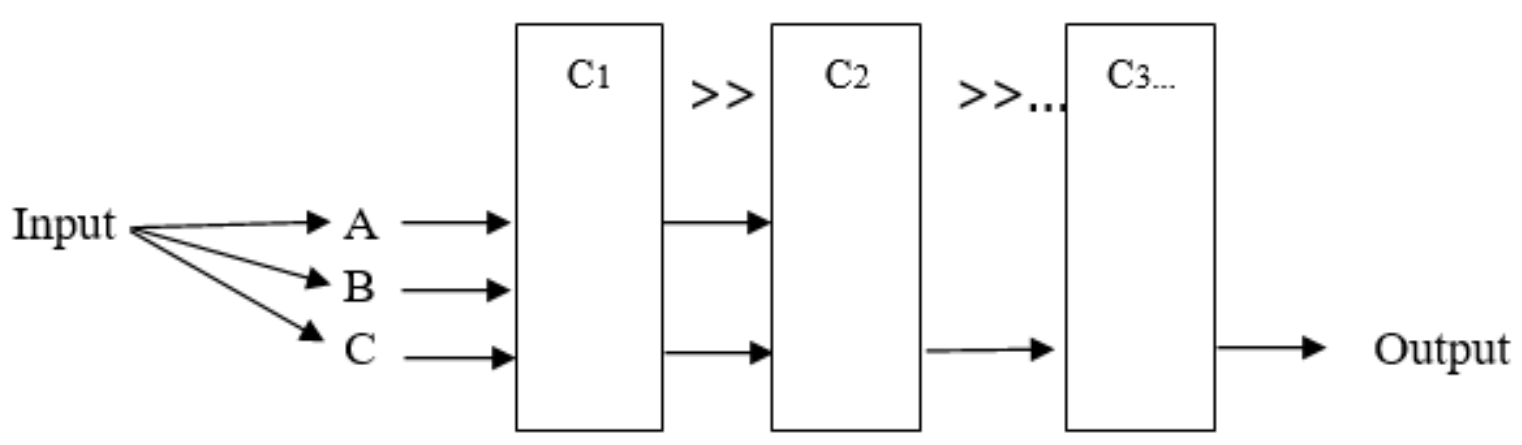

Figure 1. Input to Output Mapping in OT Grammar (Kager, 1999, p. 8)

Two types of constraints exist within the grammar of OT: Markedness and Faithfulness constraints. While Markedness constraints impose some criterion of structural well-formedness on outputs, Faithfulness constraints require that output candidates be faithful to their lexical input by preserving their input's properties (Kager, 1999).

\subsubsection{Velar Affrication}

The phonological process of (velar) affrication is not uncommon in language. Other languages besides Najdi Arabic exhibit similar affrication or fronting characteristics of consonants. In Russian, Rubach (2002) deals with palatalization of /t/ and /s/ to [t'] and [s'] before the high [-back] vowels $/ \mathrm{i} /$ and $/ \varepsilon /$. No fronting occurs in the vicinity of other back vowels. Rubach's analysis of palatalization follows from the SPE, feature geometry and OT perspective; he proposes constraints such as PAL- $i$ and PAL-e and ranks them above IDENT-V ([+back] $)$ and IDENT-C $([+$ back $])$. As a result, the palatalized form is chosen as the optimal one:

Table 2. Palatalization of /t/ in Russian (Rubach, 2002, p. 180)

\begin{tabular}{rccc} 
& PAL-i & IDENT-V $([+$ back $])$ & IDENT-C $([+$ back $])$ \\
\hline$($ a) ti & $* !$ & & $*$ \\
$\rightarrow$ (b) t'i & & $* !$ & \\
(c) ti & & & \\
\hline
\end{tabular}

In Table 2 the winning form $/ t^{\prime} i /$ incurs a violation of the least costly constraint, IDENT-C([+back]) whereas the other two runner forms are excluded by violating the higher ranked constraints, PAL- $i$, and IDENT-V([+back]). 
Kramer (2004) investigates the nature of affricates in Italian and makes use of language-specific constraints like $*_{\mathrm{z}}$ and $* \mathrm{dz}$, without alluding to the discussion of these constraints grounding. His study also proposes other identity faithfulness constraints to account for the affrication of the fricative /z/ to [dz]. The following table shows output (a) as the wining candidate:

Table 3. Affrication in Italian (Kramer, 2004, p. 7)

\begin{tabular}{|c|c|c|c|c|c|c|}
\hline & IDENT-IO(strident) & $*_{\mathrm{Z}}$ & MAX & IDENT-IO(voice) & $* \mathrm{dz}$ & IDENT-IO(stop) \\
\hline$\rightarrow(\mathrm{a}) \mathrm{dz}$ & & & & & $*$ & \\
\hline (b) $\mathrm{s}$ & & & & $* !$ & & \\
\hline (c) $\varnothing$ & & & *! & & & \\
\hline (d) $\mathrm{z}$ & & $* !$ & & & & * \\
\hline (e) $d$ & $* !$ & & & & & \\
\hline
\end{tabular}

In Table 3, candidate (a) is chosen by the Italian grammar due to the low ranking status of the constraint $* \mathrm{dz}$. Other forms are excluded by higher ranked constraints.

Note that the NA data outlined in Section 2 can easily be formalized in a rule-based generative approach (Spencer, 1996):

(26) $[\mathrm{DOR},-$ cont $] \rightarrow([\mathrm{COR},+$ delayed release $] /+\ldots$ [-cons, -back $] \_+$

The formalism in (26) reads as follows: a velar (dorsal) stop changes to a (coronal) affricate when followed or preceded by a front (-back) vowel.

Drawing on the basic tenets of the Optimality Theory, a constraint-based analysis of the Najdi Arabic affrication data can also be developed, if the following set of markedness and faithfulness constraints are invoked:

(27) IDENT-IO (cont): the value for the continuant in the input must be preserved in the output.

(28) *k-i: no velars (/k/ or $/ \mathrm{g} /$ ) can be adjacent to front vowels.

(29) *ts/dz: no affricates.

(30) $* t / d$ : no coronal stops.

The faithfulness constraint in (27) requires outputs to be faithful in their segment identity to the input; that it, outputs have to preserve the form of the input as much as possible. More specifically, identity of the continuant segment in the input has to be maintained in the output. This constraint is well-grounded in the notion of language form preservation. Linguistic change is often the outcome of a losing conflict between two forces in grammar: the driving power of change which places certain restrictions on language and results in departure from the source, as is the case with (28) above, and the need to preserve the linguistic form and resist change, as in (27) which restricts any alteration to the original form. Paradis (1996) formalizes the need to maintain the original form in the Preservation Principle (as part of a larger work on the Theory of Constraints and Repair Strategy), and should change inevitably 


\section{Macrothink}

happen, it must be least obtrusive:

(31) Preservation Principle

Segmental information is maximally preserved.

(32) Minimality Principle

Repairs should be minimal applying to the lowest phonological level.

The constraints (28-30) are markedness constraints. Recall that the environment for the allophonic affrication change in NA is restricted to syllables that contain [-back] vowels and this is captured in (28). The constraint in (29) mitigates against the occurrence of affricates while (30) prohibits coronal stops.

Arguably, the rationale for constraint (28) which forbids velars to be next to front vowels is phonetic ease of articulation. The claim is that the articulation of velars requires the tongue to be in a position further back in the mouth touching the velum (Ladefoged, 1993), while at the same time the tongue has to be advanced to the front of the mouth near the alveolar ridge for the production of front vowels. The tongue transition from back to front has to take place in milliseconds and involves some arduous manipulation of the muscles. This results in articulatory difficulty which precipitate phonological change; for easier and smoother articulation, the velars $/ \mathrm{k} /$ and $/ \mathrm{g} /$ in words like $/ \mathrm{kis} />$ [tsis] 'bag' and /gclb/ > [dzelb] 'opposite' are often changed to the coronal affricates [ts] and [dz] in anticipation of the following front vowel position. Similarly, in words like /dik/ > [dits] and /'la.sig/ > ['la.sidz] 'sticky', affrication is justified because the tongue is already in an anterior position for the front vowel and its retraction to a velar position would be quite effortful. In short, the constraint in (28) which forbids the presence of velars in proximity of front vowels is phonetically-grounded and justified.

It is crucial that constraint (28) that triggers velar affrication be ranked above the *ts/dz constraint which does not sanction the occurrence of $[\mathrm{ts}] /[\mathrm{dz}]$ affricates, as the following pairwise table illustrates:

Table 4. Ranking of *k-i over *ts/dz

\begin{tabular}{|c|c|c|}
\hline Input: /'sa.lık/ & $* \mathrm{k}-\mathrm{i}$ & $* \mathrm{ts} / \mathrm{dz}$ \\
\hline (a) ['sa.lik] & $* !$ & \\
\hline$\rightarrow \quad$ (b) ['sa.lits] & & $*$ \\
\hline
\end{tabular}

In Table 4, the faithful output (a) is eliminated on the basis of violating the higher ranked *k-i constraint. Output (b) emerges as the winner. The ranking here is crucial for NA grammar which permits velar affrication.

The faithfulness constraint IDENT-IO(cont) has to be also ranked above *ts/dz to ensure that (b) is the optimal output. Table 5 shows the relevant ranking: 
Table 5. Ranking of IDENT-IO(cont) over *ts/dz

\begin{tabular}{cccc}
\hline Input: /'sa.lik/ & IDENT-IO(cont) & $*$ ts $/ \mathrm{dz}$ \\
\hline & (a) ['sa.lis] & $* !$ & \\
$\rightarrow \quad$ (b) ['sa.lits] & & $*$ \\
\hline
\end{tabular}

Candidate (a) in Table 5 violates IDENT-IO(cont) since the plosive quality of the velar is turned into a fricative and is out (see spirantization or affrication in Trask, 1996, and Roach, 2000, for example). Candidate (b) surfaces as the acceptable form in language.

In addition, $*$ ts/dz has to be dominated by the $* t / d$ constraint that bans coronal stops in order to exclude the possibility of the velar being fronted to $[\mathrm{t}]$ or $[\mathrm{d}]$ :

Table 6. Ranking of $* \mathrm{t} / \mathrm{d}$ over $* \mathrm{ts} / \mathrm{dz}$

\begin{tabular}{llcc}
\hline Input: /'sa.lik/ & $* \mathrm{t} / \mathrm{d}$ & $*$ ts $/ \mathrm{dz}$ \\
\hline & (a) ['sa.lit] & $* !$ & \\
$\rightarrow \quad$ (b) ['sa.lits] & & $*$ \\
\hline
\end{tabular}

Candidate (a) in Table 6 alters the velar identity, but instead of turning it into a fricative, it turns it into a coronal (alveolar) stop $/ \mathrm{k} / \rightarrow$ t $]$. This is, however, ruled out by the markedness constraint $* \mathrm{t} / \mathrm{d}$ which simply disallows coronal stops leaving $(\mathrm{b})$ as the desired form.

One of the seminal tenets of OT is the notion of the Richness of the Base, which asserts that "all inputs are possible in all languages" (Prince \& Smolensky, 1993, p. 209). Thus, it is expected that given various input forms, the ranking established so far will hold no matter how different the input is:

\begin{tabular}{|l|c|c|}
\hline Input: $/ \mathbf{q} \varepsilon \mathrm{lb} /, / \mathbf{g} \varepsilon \mathrm{lb} /, / \mathbf{d z} \varepsilon \mathrm{lb} /, / \mathbf{d} \varepsilon \mathrm{lb} /, / \mathbf{z} \varepsilon \mathrm{lb} /$ & $* \mathrm{k}-\mathrm{i}$ & $* \mathrm{ts} / \mathrm{dz}$ \\
\hline (a) $[\mathbf{g} \varepsilon \mathrm{lb}]$ & $* !$ & \\
\hline$\rightarrow \quad$ (b) $[\mathbf{d z} \varepsilon \mathrm{lb}]$ & & $*$ \\
\hline
\end{tabular}

The optimal candidate (b) wins over (a) by virtue of not violating the higher ranked constraint *k-i. Instead, it violates the lower-ranked one, ${ }^{*} \mathrm{ts} / \mathrm{dz}$. The irrelevance of the input asserts the fact that the velars are in free variation with their affricate counterparts. The overall ranking for velar affrication in NA can be summed up as follows:

(33) Ranking for NA Velar Affrication

*k-i, IDENT-IO (cont), *t/d >> *ts/dz

Note how the established hierarchy of ranking in (33) requires $*$ ts $/ \mathrm{dz}$ to be dominated (lowest-ranked) by all other constraints. The ranking relationship between the rest of the constraints is irrelevant, as suggested by the comma.

The ranking in (33) can be used to account for the NA data mentioned in Section 2. For 
example, consider Tables 7 and 8 which show the OT derivation for the NA words ['?Idz.lib] 'flip' (imp.), and [tsə.'rim] 'generous':

Table 7. Ranking for NA word ['PIdz.lib] 'flip' (imp.)

\begin{tabular}{ccccc}
\hline Input: /'PIg.lib/ & $* \mathrm{k}-\mathrm{i}$ & $* \mathrm{t} / \mathrm{d}$ & IDENT-IO(cont) & $*$ ts $/ \mathrm{dz}$ \\
\hline (a) ['?ig.lib] & $* !$ & & & $*$ \\
$\rightarrow$ (b) ['?Idz.lib] & & & & \\
(c) ['?Id.lib] & & $* !$ & $* !$ & \\
(d) ['?Iz.lib] & & & & \\
\hline
\end{tabular}

Table 8. Ranking for NA word [tsə.'rim] 'generous'

\begin{tabular}{ccccc}
\hline Input: $/ \mathbf{k}$ ə.'rim/ & $* \mathrm{k}-\mathrm{i}$ & $* \mathrm{t} / \mathrm{d}$ & IDENT-IO(cont) & $* \mathrm{ts} / \mathrm{dz}$ \\
\hline (a) $[\mathrm{k} ə$.'rim] & $* !$ & & & $*$ \\
$\rightarrow$ (b) $[$ tsə.'rim] & & $* !$ & & \\
(c) $[$ tə.''rim] & & & $* !$ & \\
(d) $[$ sə.'rim] & & & & \\
\hline
\end{tabular}

The ordering between $* \mathrm{k}-\mathrm{i}$, *IDENT-IO(cont) and $* \mathrm{t} / \mathrm{d}$ is irrelevant as mentioned before. Candidate (b) in both examples emerges as the optimal one because it incurs a violation of the least ranked constraint. The same ranking hierarchy proposed in (33) should account for the examples in Section 2.3 that show no affrication. Consider Tables 9 and 10 for the words [kom] 'cuff' and [fog] 'above':

Table 9. Ranking for NA word [kom] 'cuff'

\begin{tabular}{|c|c|c|c|c|}
\hline Input: /kvm/ & $*_{\mathrm{k}-\mathrm{i}}$ & $*_{\mathrm{t} / \mathrm{d}}$ & IDENT-IO(cont) & $*_{\mathrm{ts}} / \mathrm{dz}$ \\
\hline \multicolumn{5}{|l|}{$\rightarrow$ (a) $[\mathrm{k} v \mathrm{~m}]$} \\
\hline (b) $[$ tsom] & & & & $* !$ \\
\hline (c) $[\mathrm{t} \mho \mathrm{m}]$ & & $* !$ & & \\
\hline (d) $[\mathrm{s} v \mathrm{~m}]$ & & & $* !$ & \\
\hline
\end{tabular}

Table 10. Ranking for NA word [fog] 'above'

\begin{tabular}{|c|c|c|c|c|}
\hline Input: /kom/ & ${ }^{*} \mathrm{k}-\mathrm{i}$ & $* \mathrm{t} / \mathrm{d}$ & IDENT-IO(cont) & $* \mathrm{ts} / \mathrm{dz}$ \\
\hline \multicolumn{5}{|l|}{$\rightarrow$ (a) $[$ fog] } \\
\hline (b) $[$ fodz $]$ & & & & $* !$ \\
\hline (c) $[$ fod $]$ & & $* !$ & & \\
\hline
\end{tabular}


(d) $[\mathrm{foz}]$

Note how in Tables 9 and 10 the same ranking order among the constraints stated in (33) is successful in deriving the actual non-affricated output in the NA grammar. Due to the presence of a back vowel, both [kom] 'cuff' and [fog] 'above' must realize the velar allophone only, as achieved by their compliance with all of the constraints.

\subsubsection{Factorial Typology and Theoretical Implications}

Another basic principle of Optimality Theory is that given language typology, the re-ranking of the markedness and faithfulness constraints outlined in (33) should give rise to other possible grammars. Recall that Hijazi Arabic, as discussed in Section 2, allows no affricate allophone of the velars. Instead, velars have to surface all the time whether or not they are adjacent to a front vowel within the same syllable. Consider the following same constraints discussed in 3.2.2, only re-ordered here to account for HA:

(34) Ranking for Velar Non-affrication in HA

$* \mathrm{ts} / \mathrm{dz}, * \mathrm{t} / \mathrm{d}, \mathrm{IDENT}-\mathrm{IO}$ (cont) $>>*_{\mathrm{k}-\mathrm{i}}$

Having all other constraints dominate * $\mathrm{k}-\mathrm{i}$, the non-affricated form is sure to be selected:

Table 11. Ranking for HA word [kelb] 'dog'

\begin{tabular}{ccccc}
\hline Input: $/ \mathbf{k} \varepsilon \mathrm{lb} /$ & $* \mathrm{ts} / \mathrm{dz}$ & $* \mathrm{t} / \mathrm{d}$ & IDENT-IO(cont) & $* \mathrm{k}-\mathrm{i}$ \\
\hline$\rightarrow$ (a) $[\mathbf{k} \varepsilon \mathrm{lb}]$ & & & & $*$ \\
(b) $[\mathrm{ts} \varepsilon \mathrm{lb}]$ & $* !$ & & & \\
(c) $[\mathrm{t} \varepsilon \mathrm{lb}]$ & & $* !$ & & \\
(d) $[\mathbf{s} \varepsilon \mathrm{lb}]$ & & & $* !$ & \\
\hline
\end{tabular}

Table 12. Ranking for HA word [gelb] 'opposite'

\begin{tabular}{ccccc}
\hline Input: $/ \mathbf{q} \varepsilon \mathrm{lb} /$ & $* \mathrm{ts} / \mathrm{dz}$ & $* \mathrm{t} / \mathrm{d}$ & IDENT-IO(cont) & $* \mathrm{k}-\mathrm{i}$ \\
\hline$\rightarrow$ (a) $[\mathbf{g} \varepsilon \mathrm{lb}]$ & & & & $*$ \\
(b) $[\mathbf{d z} \varepsilon \mathrm{lb}]$ & $* !$ & & & \\
(c) $[\mathbf{d} \varepsilon \mathrm{lb}]$ & & $* !$ & & \\
(d) $[\mathbf{z} \varepsilon \mathrm{lb}]$ & & & $* !$ & \\
\hline
\end{tabular}

Some dialects of Janubi Arabic in Saudi Arabia systematically replace the velar $/ \mathrm{k} / \mathrm{with}$ [s] or [J], not [ts]. In other words, these dialects show cases of fricativization or spirantization rather than affrication. Words such as /fik/ 'in you (fem)' and /bertik/ 'your (fem) house' are often realized as [fis]/[fif] and [beitis]/[beitIJ]. Again, the grammar of such dialects can easily be captured through reordering the ranking of the faithfulness and markedness constraints discussed so far: 
(35) Ranking for Velar Fricativization in Janubi Arabic

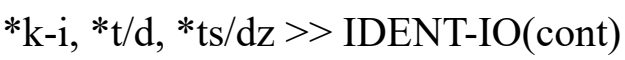

Table 13. Ranking for Janubi Arabic word [fik] 'in you (fem)'

\begin{tabular}{ccccc}
\hline Input: $/$ fik/ & $* \mathrm{k}-\mathrm{i}$ & $* \mathrm{t} / \mathrm{d}$ & $* \mathrm{ts} / \mathrm{dz}$ & IDENT-IO(cont) \\
\hline (a) $[\mathrm{fik}]$ & $* !$ & & & \\
(b) $[\mathrm{fits}]$ & & $* !$ & \\
(c) $[\mathrm{fit}]$ & & $* !$ & $*$ \\
$\rightarrow$ (d) $[\mathrm{fis}] /[\mathrm{fi}]]$ & & & & \\
\hline
\end{tabular}

Other instances of velar realization in different Arabic dialects can be accounted for with the same set of constraints proposed in (33). What changes to reflect the different grammars of these dialects is the relative ranking ordering between the constraints. Even within one dialect, recall that NA alternates between the affricated and non-affricated forms. Such alternation between the allophonic variants can be explained in OT terms by assuming that NA speakers sometimes rank $* \mathrm{k}$-i higher than $* \mathrm{ts} / \mathrm{dz}$ (to derive affricated forms), while in other cases *k-i gets demoted below all other constraints (to derive non-affricated forms).

One important theoretical implication of the OT analysis is the direct mapping from input to output, disregarding any intermediate phonological representation. Previous phonological generative-based approaches posited such intermediate levels of analysis (Kager, 1999). With that came rule ordering, feeding/bleeding rules, lexical and post-lexical application of rules...etc. One advantage of an OT-based analysis is that it posits no intermediate levels of representation due to the overwhelming generative power of GEN (Generator) which theorizes that any output is possible, but only one optimal output wins. Optimality, therefore, is determined by the candidate that incurs the least violation of some language-specific hierarchy of constraints. As it stands, the OT analysis presented in this paper accounts for all of the data in Section 2; however, the NA informant in this study provided some further conflicting data which seem to be problematic to the argument made in 3.2.2. Consider the following sets of words spoken in NA:
$(36) / 1 \mathrm{Ik} / \quad \rightarrow$ NA. [lits] *[1 Ik $]$
'for you (fem)'
(37) $/ 1 \mathbf{l k} /$
$\rightarrow$ NA. [lik] $*$ * [lits $]$
'for you (mas)'

There are a few things to take note of in these examples. For one thing, the velar $/ \mathrm{k} / \mathrm{appears}$ to exhibit affrication when the addressee is feminine as in (36), but not when the addressee is masculine as in (37) although the licensing phonological environment is met in both words: in both words, the velar is adjacent to the front vowel /I/. Note further that the velar affrication in (36) is obligatory, not optional as in all of the data in Section 2. It appears that the gender of the addressee in (36) and (37) plays a role in the process of affrication here; the need for language speakers to maintain a distinction between feminine and masculine forms could have forced affrication in (36) and blocked it in (37).

However, further examination of the origin of the words in (36) and (37) reveals that in 
Classical Arabic the feminine word for the phrase 'for you' is /'le.ki/, and the masculine one is $/$ 'le. $\mathbf{k N} /$. The following depicts the change that took place in the derivation of these words:

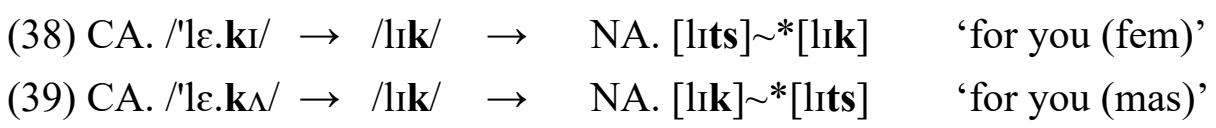

The presence of the front vowel / $\mathrm{I} /$ next to the velar in (38) is what triggered affrication. By the same token, in (39) the absence of a front vowel in the second syllable of the CA word is what prevented velar affrication. In other words, it can be argued that the phonological context solely determines the occurrence of the affricated velar; gender in and of itself has nothing to do with triggering velar affrication. This argument can indeed be corroborated by further data from the NA informant:
$(40) /$ fik- $\varepsilon t / \rightarrow$ NA. [fits- $\varepsilon t] \sim[$ frk- $-\varepsilon t]$
'it (fem) has been opened'
$(41) / \mathrm{fik} / \rightarrow$ NA. [fits] $\sim$ fik $]$
'it (mas) has been opened'

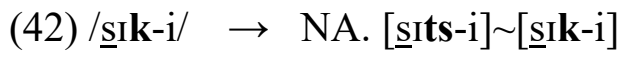
'close imp. (fem)'
$(43) / \underline{s} \mathbf{k} / \rightarrow$ NA. [ㅍts] $\sim[\underline{s} I k]$
'close imp. (mas)'

Velar affrication in these examples rules out gender as a possible cause. In both (40) and (41) the velar $/ \mathrm{k} /$ is realized as [ts], besides the faithful allophone [k], irrespective of the addressee gender. The same is true for (42) and (43). Note that NA expresses gender distinction here by the overt $-\varepsilon t$ and $-i$ clitics.

To sum up, it appears that the process of velar affrication is subject to an intermediate level of representation, and that its application must take place prior to vowel deletion in (38) and (39). Under a generative rule-based approach, such generalization can be achieved through rule ordering, thus giving rise to counter-feeding opacity:

(44) Rule Ordering between Affrication and Vowel Apocope

\begin{tabular}{|c|c|}
\hline UR: & le.kI \\
\hline Velar-Affrication: & le.tsI \\
\hline Vowel Change: & 1I.tsI \\
\hline Vowel Apocope: & lits \\
\hline SR. & lits \\
\hline
\end{tabular}

However, while the rule-based derivation in (44) accounts for the discrepancy between (36) and (37), the under-application of affrication in (37) presents a clear example of opacity, which is problematic for an approach that posits no intermediate levels of representation. The notion of opacity is defined as:

the phenomenon that output forms are shaped by generalizations that are not surface-true.

Opaque generalizations lurk at a level deeper than the output, which becomes apparent by 'peeling off' effects overlaid by other surface true generalizations. (Kager, 1999, p. 372)

Thus, the ranking of the constraints for NA velar affrication stated in (33) would erroneously predict the application of velar affrication in (37). While an extensive discussion of opacity is beyond the scope of this paper, one possible solution to circumvent the problem of opacity in OT is the introduction of output-output-correspondence constraints (Benua, 1995; Kager, 1999; McCarthy, 1998). For the analysis of affrication in NA, the following output-output- 
constraint on identity is required:

(45) IDENT-BASE(place)

This identity faithfulness constraint ensures that the place of articulation in the base form is preserved in the output:

Table 14. Ranking for NA word [lik] 'for you (mas)'

\begin{tabular}{|c|c|c|c|c|c|}
\hline $\begin{array}{l}\text { Input: 1Ik } \\
\text { Base: } 1 \varepsilon . \mathbf{k} \Lambda\end{array}$ & IDENT-BASE (place) & $* \mathrm{k}-\mathrm{i}$ & $* \mathrm{t} / \mathrm{d}$ & IDENT-IO(cont) & $* \mathrm{ts} / \mathrm{dz}$ \\
\hline$\rightarrow$ (a) 1ık & & $*$ & & & \\
\hline (b) lits & $* !$ & & & & * \\
\hline (c) lis & $* !$ & & & $*$ & \\
\hline (d) lit & $* !$ & & * & & \\
\hline
\end{tabular}

Table 14 demonstrates how IDENT-BASE(place) interacts with other constraints to obtain the desired candidate. The outputs (b-d) all incur fatal violations of high ranking IDENT-BASE(place), and are excluded early in the competition. Candidate (a) emerges as the winner in the grammar.

\section{Conclusion}

This short paper examined the behavior of velars with regard to affrication in two dialects of Arabic, Najdi and Hijazi Arabic. Two native speakers of these dialects provided the data for this study. It is argued that the affricated [ts] and [dz] allophones of the velars $/ \mathrm{k} / \mathrm{and} / \mathrm{g} /$ are in free variation with the non-affricated allophones. Velars sometimes undergo affrication when close to front vowels only in NA, but not HA. The allophonic alternation of $/ \mathrm{k} / \sim[\mathrm{ts}]$ and $/ \mathrm{g} / \sim[\mathrm{dz}]$ can be captured by proper ranking of faithfulness and markedness constraints under an Optimality Theoretic approach. As a corollary of language typology, the re-ranking of markedness and faithfulness constraints accounts for lack of affrication in the Hijazi grammar, and can also account for different realizations of the velars in other dialects of Arabic. The paper also discusses under-application of affrication in some contexts, and the use of output-output constraints to overcome opacity in the Najdi Arabic data is suggested.

\section{References}

Abdel Baqi, D. (1985). Lughat Tamim: Dirasaat Tariykhiyaah Wasfiiyyah. Cairo, alhaiaa alammah lishuun almataabi alamiryyah.

Al-Shahrani, S. (1988). The phonology of the spoken Arabic of the Shahran tribe in southern Saudi Arabia. The University of Michigan, Ann Arbor.

Al-Sharkawi, M. (2016). History and development of the Arabic language. Routledge Pub. https://doi.org/10.4324/9781315743271

Benua, L. (1995). Identity effects in morphological truncation, in J. Beckman, L. Walsh-Dickey \& S. Urbanczyk (eds), University of Massachusetts Occasional Paper in Linguistics 18, Papers in Optimality Theory, GLSA, Amherst. 


\section{Macrothink}

Education and Linguistics Research

ISSN 2377-1356 2020, Vol. 6, No. 2

Brustad, K. (2000). The syntax of spoken Arabic. Washington: Georgetown University Press.

Ingham, B. (1994). Najdi Arabic central Arabian. London: John Benjamins Publishing Company. https://doi.org/10.1075/loall.1

Johnstone, T. M. (1967). Eastern Arabian dialect studies. London, Oxford University Press.

Kager, R. (1999). Optimality theory. Cambridge University Press. https://doi.org/10.1017/CBO9780511812408

Kramer, M. (2004). Affricates and the phonetic implementation of laryngeal contrast in Italian.

Ladefoged, P. (1993). A course in phonetics. Harcourt Brace Jovanovich College Pub.

McCarthy, J. (1998). Sympathy and phonological opacity. University of Massachusetts.

Paradis, C. (1996). The inadequacy of filters and faithfulness in loanword adaptation.

Prince, A., \& Smolensky, P. (1993). Optimality theory: Constraint interaction in generative grammar.

Roach, P. (2000). English phonetics and phonology. Cambridge University Press.

Rubach, J. (2002). An overview of palatalization $-i$. Studies in Phonetics, Phonology and Morphology, 8(2), 169-186.

Sibawayh, A. (2009). Al-Kitaab. Dar Al-Kutub Al-Ilmiyah.

Spencer, A. (1996). Phonology: Theory and description. Oxford: Blackwell Publishers Ltd.

Trask, R. L. (1996). Historical linguistics. London: Edward Arnold.

Watson, J. C. (2007). The phonology and morphology of Arabic. Oxford: Oxford University Press.

\section{Copyright Disclaimer}

Copyright reserved by the author(s).

This article is an open-access article distributed under the terms and conditions of the Creative Commons Attribution license (http://creativecommons.org/licenses/by/4.0/). 